\title{
Potential and actual productivity of stem wood in forestry ${ }^{1}$
}

\section{J. H. BECKING}

Department of Forestry, Agricultural University, Wageningen, Netherlands

\section{Summary}

PATERSON developed a general index for the estimation of the potential productivity of stem wood in $\mathrm{m}^{3}$ per ha of forests in different regions. He used only climatic factors in his formula, excluding the quality of the soil by merely considering ideal site classes.

WECK revised PATERSON's formula by a better definition of the length of the annual growth period and by relating the index to the total dry-matter productions in tons per ha. He calculated the stem-wood production in tons per ha by deducting the losses by respiration, leaf shed and branches + roots from the total dry-matter production. He estimated these losses in the temperate regions on $44 \%, 13 \%$ and $11 \%$ respectively, resulting in a stem-wood output of $32 \%$. For the tropics these losses should be $55 \%, 21 \%$ and $11 \%$ respectively, giving a stem-wood output of $14 \%$.

After the opinion of the writer the higher loss by leaf shed in the tropics assumed by WECK is not justified and can better be determined on the same level as in the temperate regions, owing to which the stem-wood output in the tropics should be raised to $21 \%$.

WECK calculated also the absolute stem-wood productions in tons per ha for different forest types. He found that the stem-wood production will culminate in the temperate rain forest.

Following my assumption, the stem-wood productions in the tropical lowland and mountain rainforests will surpass those in the temperate regions considerably.

Finally, the actual stem-wood productions in dry-matter tons per ha of a number of West European and tropical tree species after the available yield tables are compared.

The ratio of the average of these productions $(1: 2,5)$ reasonably agrees with that for the potential estimations following the revised climatic index $(1: 2,3)$.

I wish to express my appreciation that in this series of lectures on the productivity of crop plants also forestry has been drawn into the discussion.

Before starting with the topic in detail I should like to point out some general differences between forestry and agriculture.

First, labour intensity in forestry is 7 to 14 times lower than that in agriculture. Moreover, the growth period (time before harvesting) in forestry accounts as many decades in years as it is months in agriculture. Because of these circumstances forestry production is bound to much larger units as in agriculture and in consequence its production is far more inflexible. On the other hand, in forestry no sharply defined point of ripeness of the product exists. Therefore, it is possible to anticipate or to postpone the final harvest several years without any appreciable loss. This flexibility in harvest time makes it possible for the producer to take advantage of the price fluctuations in the woodmarket.

1 Lecture held at the course "Fundamentals of dry-matter production and distribution" organized by the Royal Netherlands Society for Agricultural Sciences, Wageningen, 10th January, 1962. 
Finally, there is a considerable difference in the size of the plants. The height of many crop plants is not more than 40 to $70 \mathrm{~cm}$, whereas it is 40 to 70 meters for forest trees. Moreover, forest stands are often mixed with other wood species arranged in different vertical layers. These circumstances make it comprehensible that experimental research in forest stand is far more complicated than in agriculture and, therefore, rather seldom carried out.

For this reason the data on the productivity of stem wood are without any doubt much less exact than those obtained for the agricultural plants given in the other lectures.

In spite of this I hope, however, that my more or less speculative considerations on the stem-wood productivity of forest trees in different climatic regions will give still some points of contact with the yield production of agricultural plants.

In 1956, the Swedish geographer Paterson developed a general index for the estimation of the potential vegetative productivity of forest regions. According to his opinion, the potential productivity is mainly dependent on climatic factors. The quality of the soil would also to a great extend affect the productivity, but PATERSON excluded this factor by merely considering ideal site classes. He defined only the productivity of normal stands on the best sites.

As climatic index for the potential vegetative productivity (CVP) PATERson developed the following formula:

$$
\text { CVP }=\frac{T_{v} \cdot P \cdot G \cdot E}{T_{a} \cdot 12 \cdot 100} .
$$

In this formula the heat of the climate is expressed by the relation between the mean temperature in the hottest month of the year $\left(T_{v}\right)$ and the temperature amplitude of the hottest and the coldest months of the year $\left(T_{2}\right)$, both noted in degrees of Celsius. The humidity of the climate is taken into account by the mean yearly rainfall $\mathbf{P}$ in $\mathrm{mm}$. The next climatic factor incorporated into the formula is the length of the annual growth period presented in months but transferred in years by dividing it by 12 .

The number of months of the annual growth period is defined by the drought index of DE Martonne:

$$
i=\frac{12 \cdot p}{(t+10)}
$$

in which formula $\mathrm{p}=$ the main rainfall in $\mathrm{mm}$ and $\mathrm{t}=$ the mean temperature in degrees of Celsius belonging to the month concerned. All months with a drought index of more than 20 are counted to fall into the growth period.

Finally, a percentual reduction factor for the evapotranspiration (E) is included. This reduction factor is defined according to MILANKovitch's relation between the radiation energy at the pole and that of the latitude concerned with absence of the atmosphere.

In this way PAterson marked a number of potential production values of stem wood in $\mathrm{m}^{3}$ per ha in a graph in relation to the logarithms of the climatic indices. The points obtained could be smoothed out by a straight line.

Forest vegetation starts with a CVP-value of 25 and for the higher values the potential productions of stem wood are given in TABLE 1 . 
Table 1. Potential productions of stem-wood after the CVP-index of Paterson

\begin{tabular}{cccc}
\hline CVP & $\begin{array}{c}\text { Stem-wood } \\
\text { production } \\
\left(\mathrm{m}^{3} / \mathrm{ha}\right)\end{array}$ & CVP & $\begin{array}{c}\text { Stem-wood } \\
\text { production } \\
\text { (m3/ha) }\end{array}$ \\
$25-100$ & 2,1 & $2.000-3.000$ & 10,4 \\
$100-200$ & 4,1 & $3.000-5.000$ & 11,5 \\
$200-300$ & 5,2 & $5.000-10.000$ & 12,9 \\
$300-500$ & 6,3 & $10.000-20.000$ & 14,5 \\
$500-1.000$ & 7,7 & $20.000-30.000$ & 15,6 \\
$1.000-2.000$ & 9,3 & & \\
\hline
\end{tabular}

The production of PAterson arose much interest in forestry.

A further analysis of PATERson's formula lead, however, to the conclusion that some alterations should be made. These alterations summarized by WECK (1957) are :

1. the potential production of stem wood can better be expressed in tons of dry matter instead of $\mathrm{m}^{3}$, because the specific gravity of wood varies widely, i.e. from 0,1 to 1,2 ;

2. the estimation of the length of the annual growth period following the drought index of DE MARTONNE was not quite satisfactory. It was necessary to add that the mean monthly temperature should be at least $10^{\circ}$ Celsius, and the growth period should cover at least two months;

3. a better definition would be the relation between the climatic index (CVP) and the total dry-matter production, as the stem-wood output will vary in different climatic regions.

Applying these alterations WECK defined the potential total dry-matter productions in tons per ha with the different values of CVP given in TABLE 2.

TABLE 2. Potential total production of dry matter in tons/ha after the CVP-index of Paterson, revised by Weck

\begin{tabular}{cccc}
\hline CVP & $\begin{array}{c}\text { Dry-matter } \\
\text { production } \\
\text { (tons/ha) }\end{array}$ & CVP & $\begin{array}{c}\text { Dry-matter } \\
\text { production } \\
\text { (tons } / \text { ha) }\end{array}$ \\
38 & 0,5 & 100 & 10,0 \\
40 & 1,0 & 164 & 15,0 \\
44 & 2,0 & 280 & 20,0 \\
49 & 3,0 & 465 & 25,0 \\
55 & 4,0 & 770 & 30,0 \\
61 & 5,0 & 2.130 & 40,0 \\
67 & 6,0 & 5.800 & 50,0 \\
75 & 7,0 & 16.000 & 60,0 \\
82 & 8,0 & 45.000 & 70,0 \\
91 & 9,0 & 125.000 & 80,0 \\
\hline
\end{tabular}

Only a relatively small part of the total dry-matter production of forest trees is stem wood.

The investigations of BOYSON-JENSEN (1932) and his co-workers carried out in a beech forest in Denmark showed that the losses of the total dry-matter production 
due to respiration, leaf shed and branches + roots were $44 \%, 13 \%$ and $11 \%$ respectively. Hence, for the stem-wood production only $32 \%$ remains. This stemwood output, however, will not be the same in different geographic regions because of climatic differences.

For instance the loss of dry matter by respiration will be considerably higher in the tropics than in temperate regions. WECK estimated this loss in the tropics to be $55 \%$, whereas only $44 \%$ in the temperate regions. This higher estimation seems reasonably to me.

Besides this, WECK's estimation that the loss of dry matter by leaf shed is $20 \%$ in the tropics compared to $13 \%$ in the temperate regions, was based on the assumption that trees in the tropics shed their leaves 3 times within 2 years. According to me, this opinion is very doubtful and needs confirmation. In this respect I should like to refer to two recent publications on the composition of forest stands in temperate and tropic region, respectively.

Ovington and MADGWICK (1959) analized the composition of a 55 years old birch stand in England. Its dry-matter composition was:

\begin{tabular}{|c|c|c|c|c|c|}
\hline Leaves & $=$ & 2,5 & tons & per & ha \\
\hline Branches & $=$ & 28,7 & " & " & " \\
\hline Roots & $=$ & 49,8 & $"$ & $"$ & $"$ \\
\hline Stem wood & $=$ & 134,5 & " & ", & " \\
\hline Total & & 215,5 & ons & per & ha \\
\hline
\end{tabular}

The share of stem wood in the total dry-matter production, therefore, was $62,4 \%$. BOYSEN-JENSEN found a share of stem-wood production of $57,1 \%$ for a beech forest in Denmark. Averaging the two data, the stem-wood share in the temperate region will be about $60 \%$.

GREENLAND and KowAL. (1960) made a comparable investigation in a primary rainforest in Ghana. The composition of this forest was :

\begin{tabular}{|c|c|c|c|c|c|}
\hline Leaves and branches & $=$ & 25,5 & tons & per & ha \\
\hline Lianes & $=$ & 14,5 & " & $"$ & " \\
\hline Stumps & $=$ & 49,0 & $"$ & $"$ & $"$ \\
\hline Roots & $=$ & 24,8 & ", & $"$ & \\
\hline Stem wood & $=$ & 173,4 & ", & ", & ", \\
\hline
\end{tabular}

Hence, also in this case the share of stem wood in the total dry-matter production was about $60 \%$.

The figures cited above show that there are no appreciable differences in the stemwood shares of forests in temperate and tropic regions. Therefore, the assumption of WECK that the loss by leaf shed will be much higher in the tropics than in temperate regions, does not seem to be justified.

WECK calculated the stem-wood output on $100 \%-55 \%$ (loss by respiration) $20 \%$ (loss by leaf shed) $-11 \%$ (loss by roots + branches) $=14 \%$ of the total dry-matter production.

As stated above, according to my view it is better to estimate the losses by leaf shed in the tropics to be at the same level as those in temperate regions, so the stem-wood output in the tropics should be raised to $21 \%$. 
In the temperate region the stem-wood output is $32 \%$ according to the above mentioned investigations of BoYSEN-JENSEN.

The relative output in the temperate region, therefore, is also higher, which is in agreement with some results obtained with agricultural plants.

Next to the relative output, also the absolute stem-wood production in tons of dry matter per ha is of interest.

In a later publication by WECK, the absolute stem-wood production in tons of dry matter per ha was calculated for different forest types. His results are presented in TABLE 3, together with my estimations.

After the calculation of WECK the maximal stem-wood production will reach 9,3 tons per ha in the temperate rain forest, while the production of the tropical lowland rain forest will be 13,2 tons per ha according to my own estimation. As evident from TABLE 3 also the stem-wood production of the tropical mountain forests will surpass that of the temperate forest types.

TABLE 3. Stem-wood production in tons/ha of dry matter for different forest types after WECK and BECKING

\section{Forest types}

Total
potential
dry-matter
production
(tons $/$ ha)

$$
0,14
$$$$
8,8
$$

\begin{tabular}{cc}
\hline \multicolumn{2}{c}{ WECK } \\
\hline $\begin{array}{c}\text { Relative } \\
\text { output }\end{array}$ & $\begin{array}{c}\text { Dry matter } \\
\text { (tons } / \text { ha) }\end{array}$
\end{tabular}

Potential stem-wood production

1. Tropical lowland rainforest $(0-500 \mathrm{~m}$ above sea level)

2. Tropical mountain rainforest $(500-1500 \mathrm{~m}$ above sea level)

...

3. Temperate rainforest (Valdivia, Nagasaki, Valencia)

4. West European forests

$\begin{array}{lllll}54.6 & 0,14 & 7,6 & 0,21 & 11,5 \\ 31.0 & 0,30 & 9,3 & 0,30 & 9,3 \\ 18.0 & 0,32 & 5,8 & 0,32 & 5,8\end{array}$

The ratio between the potential stem-wood productions of West European forests and tropical lowland rainforest after WECK will be $1: 1,4$ and according to my estimation $1: 2,3$.

Finally, I should like to compare the actual stem-wood production in dry-matter tons per ha of tropical with that of West European forests. For this purpose I will use the available yield tables of a number of tropical and West European wood species.

For this comparison WECK chose the average production of the two best site classes. Following the original intension of PAterson according to me it is better to use only the very best site class, such also on account of the fact that the number of site classes of the tree species concerned varies from 3 to 7 . I further found it desirable to make a distinction between coniferous and broad-leaved tree species.

In TABLE 4 the first column gives the average stem-wood production values with the usual rotations in years. In the following column the specific gravity of air-dry 


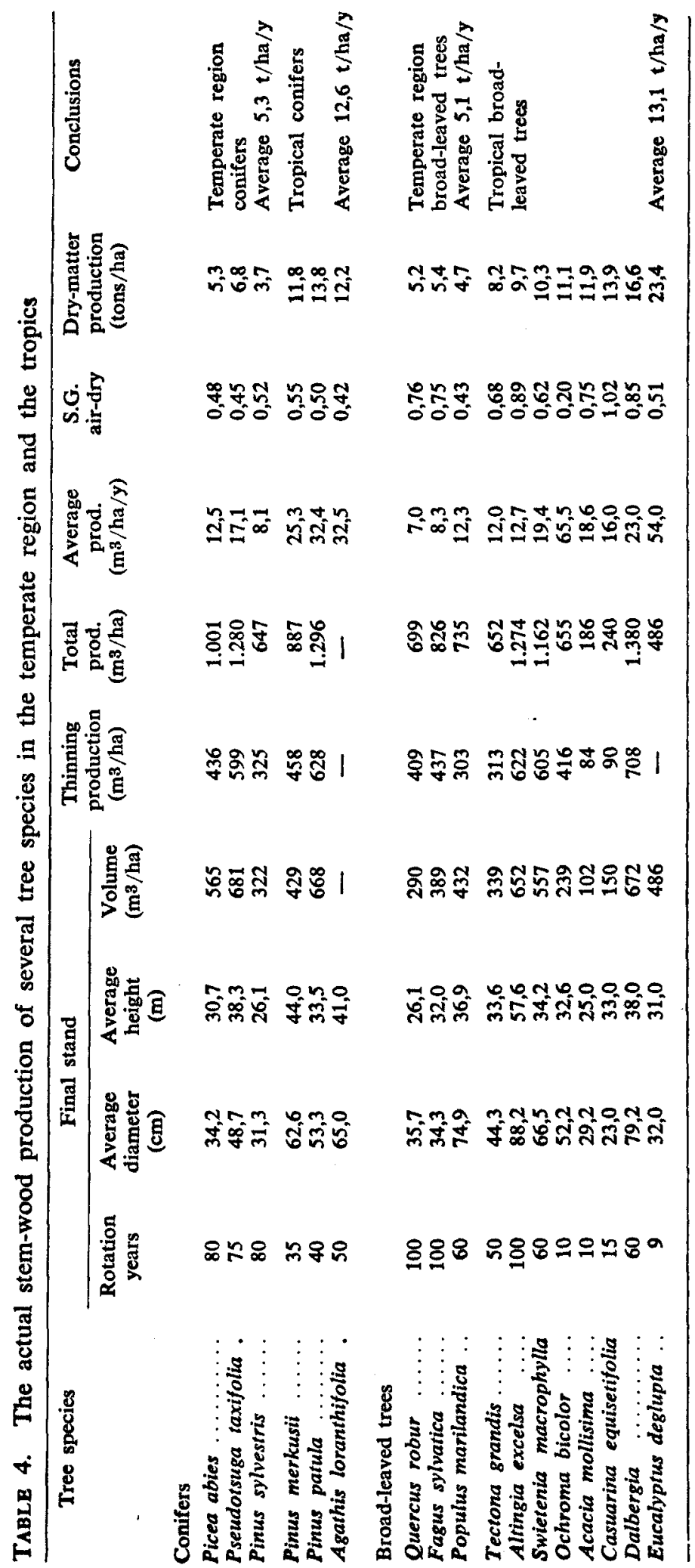


wood is given and with this figure the dry-matter production in tons per ha was calculated taking into account that the moisture contents of air-dry wood in tropical and temperate regions are $15 \%$ and $12 \%$ respectively.

In addition, TABLE 4 shows that the ratio between dry matter stem-wood production of West European and tropical tree species amounts to $1: 2,4$ for the conifers and to $1: 2,6$ for the broad-leaved species, giving an average of $1: 2,5$.

This ratio for the actual stem-wood production reasonably agrees with that for the potential production estimations following the revised climatic index of Paterson $(1: 2,3)$. The latter climatic index is, therefore, suitable for rough estimations in different climatic regions.

Further, LIETH (1961) pointed out that the relation for the stem-wood production of West European and tropical tree species calculated above differs only to a small extent from the relation given by BRAY and GORHAM for the litter production in both regions $(1: 2)$ and also from the relation of the dry-matter production of a Thypha-Phragmites vegetation in the temperate region compared to Saccharum in the tropics $(1: 2,3)$.

It will be clear, however, that the actual productivity values in a certain climatic region will widely vary with the quality of the soil and the special characteristics of the tree species concerned. The climatic index is, therefore, less suitable for estimations of the potential productivity in special cases. It can only be used as a rough general estimation for productivity in different climatic regions.

\section{I T ER A T URE}

BoYson-JENSEN, $P$.

Greenland, D. J., and J. M. L. KowaL

LIETH, $H$.

Ovington, J. D., and H. A. MADGWICK

Paterson, S. S.

WECK, J.
1932 Die Stoffproduktion der Pflanzen. Verlag G. Fischer, Jena.

1960 Nutrient content of the moist tropical forest of Ghana. Plant and Soil.

1961. Die Stoffproduktion. Symposium Hohenheim, 1961.

1959 The growth and composition of natural stands of birch. Plant and Soil.

1956 The forest area of the world and its potential productivity. Göteborg.

1957 Neuere Versuche zum Problem der Korrelation: Klima und forstliches Produktionspotential. Forstarchiv.

1959 Regenwälder, eine vergleichende Studie forstlichen Produktionspotentials. Die Erde. 